\title{
Poem (Lyric)
}

\section{Rhythm}

Shiqin Xu, M.D., M.P.H.; Xiaofeng Shen, M.D., M.P.H.; Fuzhou Wang, M.D., Ph.D.

Life is the rhythmic song needing to play with heart. Medicine is the tuner for the rhythmic life.

Lie on the table

On

The lights

Still

The room

A soft voice

Muffled

Counts backward from a hundred

Until

Slows to a stop

The rhythm of numbers

Never gets to one

Signs

Checked

Surgeries

Going on

The beeps

Speed up

The beeps

Slow down

It's tempo for the surgeon

The symphony

A never-before tried version

Being conducted

The bass player

The anesthesiologist

Stick on the metronome

Repeated

Or

Impromptu

Ensures the beeping rhythm

In good pace

Ups and downs

The wind out 
The wind in

The ventilator

Ensures air supply

Has not a single disruption

The soloist

Plays instruments

With steady hands

From hand to hand

Beautifully

The heart

In rhythm

Time marched on

The pace

The rhythm

Kept

Until

The piece

Completed

No cheers

No standing ovations

But

The doctors knew

They had succeeded

\section{AUTHOR INFORMATION}

Author Affiliations: Department of Anesthesiology, Hospital of Obstetric and Gynecology, Affiliated to Nanjing Medical University, Nanjing 210004, China (Xu, Shen, and Wang).

Correspondence to: Dr. Fuzhou Wang, MD, PdD, Email: zfwang50@njmu.edu.cn
Conflict of Interest Disclosures: The author declared no competing interests of this manuscript submitted for publication.

Acknowledgement: None.

Funding/Support: N/A

Role of the Funder/Sponsor: N/A
How to Cite This Paper: Xu S, Shen X, Wang F. Rhythm. Sci Insigt. 2018; 2018:e000167.

Digital Object Identifier (DOI):

http://dx.doi.org/10.15354/si.18.PO009.

Article Submission Information: Received, July 22, 2018; Revised: July 26, 2018; Accepted: July 26, 2018. 